\title{
DNA replication stress and cancer: cause or cure?
}

Elaine M Taylor* and Howard D Lindsay

Lancaster Medical School, Faculty of Health and Medicine, Lancaster University, Lancaster, LA1 4YG, UK

* Author for correspondence:

Tel.: (01524) 593608

e.m.taylor@lancaster.ac.uk 


\section{Summary}

There is an extensive and growing body of evidence that DNA replication stress is a major driver in the development and progression of many cancers, and that these cancers rely heavily on replication stress response pathways for their continued proliferation. This raises the possibility that the pathways that ordinarily protect cells from the accumulation of cancer-causing mutations may actually prove to be effective therapeutic targets for a wide range of malignancies. In this review we explore the mechanisms by which sustained proliferation can lead to replication stress and genome instability, and discuss how the pattern of mutations observed in human cancers are supportive of this oncogene-induced replication stress model. Finally we go on to consider the implications of replication stress both as a prognostic indicator and, more encouragingly, as a potential target in cancer treatment.

\section{Keywords}

Replication stress, genome instability, oncogenes, ATR, CHK1 
Despite profound differences between diverse cancer types, virtually all cancer cells share certain characteristics. These properties, termed hallmarks of cancer, include sustained proliferative signalling and evasion of growth suppressors, replicative immortality, escape from apoptosis and from immune destruction, tissue invasion and metastasis, activation of angiogenesis, deregulated cellular energetics, tumour promoting inflammation and genome instability [1]. Of these, genome instability is regarded as a key driving force in cancer progression, since it can facilitate the acquisition of other cancer hallmarks and, consistent with this, is observed early during tumorigenesis [2, 3].

In hereditary cancers, genome instability has often been linked to the loss of DNA repair functions. Defective DNA repair can increase the mutation rate, thereby enhancing the likelihood of accruing further changes that promote tumorigenesis, as predicted by the mutator hypothesis [4]. However, extensive sequencing of cancer genomes during the last decade has revealed that, in actual fact, mutations targeting these so-called 'caretaker' genes are relatively rare in sporadic cancers, particularly in early tumour development [5]. Instead, the genes most frequently mutated in sporadic cancers relate to sustained proliferation and evasion of cell death [5,6]. Moreover, it is clear that these cancer 'driver' mutations arise in a particular order during tumour development, with mutations in oncogenes or tumour suppressors, which trigger proliferation, preceding mutations in genes, such as TP53, which allow cells to evade apoptosis or senescence.

The fact that oncogene activation and genome instability are both early features of cancer development, together with the observation that oncogene activation is sufficient to induce genome instability in various experimental models, has led to the proposal that oncogene-induced DNA damage is the early driver of tumorigenesis $[2,3,7,8]$. According to this model, cell proliferation, prompted by oncogene activation or tumour suppressor loss, induces DNA replication stress [3, 911]. This replication stress results in DNA damage and triggers a robust DNA damage response in precancerous lesions, activating the ATM/TP53/MDM2 checkpoint pathway and leading to cell cycle arrest, apoptosis or senescence. In this situation the DNA damage checkpoint serves as a barrier to tumorigenesis. However, the continued presence of genome instability means that eventually this barrier may be breached as mutations arise which disable this checkpoint, thus conferring a proliferative advantage and driving tumour progression (Figure 1). In this review, we consider the mechanisms by which oncogene activation can lead to replication stress and genome instability in many tumour types, and then go on to explore the implications that this has for cancer treatment.

\section{Causes of DNA replication stress}

The object of DNA replication is to precisely duplicate the genome, prior to cell division. To achieve this, DNA replication machinery is assembled at thousands of replication origins, in a two-step process. First, a pre-replicative complex is formed at each origin during origin licensing. Then, in a temporally controlled fashion throughout $\mathrm{S}$ phase, a sub-set of these licensed origins are activated, leading to complete replisome assembly and the establishment of bidirectional replication forks. These replication forks travel outwards from the fired origin, generating new DNA copies, until they meet with converging forks and, ultimately, replication of the entire genome is achieved. Replication stress occurs when this tightly co-ordinated replication program is disrupted, either by impediments 
to fork progression that result in fork stalling or collapse, or through deregulated origin licensing or firing, as discussed below.

\section{Impaired fork progression}

A variety of physical obstacles can inhibit replication fork progression. For example, DNA damage which has not yet been repaired, ribonucleotides misincorporated by the replicative polymerase in place of deoxyribonucleotides, or DNA-protein complexes ahead of the replication fork will all cause fork stalling, and must somehow be bypassed for the fork to advance [12]. Moreover, the highly stable secondary structures that form at certain DNA sequences, such as hairpins at trinucleotide repeats or the G-quadruplex structures that can form in GC-rich DNA, are intrinsically difficult to unwind and to replicate through [13].

Since both DNA replication and transcription act on the same DNA template, conflicts between these two processes can also occur. Normally, DNA replication and transcription are spatio-temporally regulated in order to limit this interference. Nevertheless, the recent identification of early replicating fragile sites (ERFSs), highly transcribed regions of the genome whose marked susceptibility to replication stress is transcription-dependent, supports that notion that gene expression can be a significant source of replication stress [14]. How, mechanistically speaking, transcriptional interference leads to replication stress is still not entirely clear. One possibility is that head-on collisions between the replication and transcription machinery could cause fork stalls, while evidence from yeast studies suggests that, even before collision, an increase in positive supercoiling between a converging replication fork and RNA polymerase II can block fork progression [15]. RNA:DNA hybrids known as R-loops can also form during transcription when the nascent RNA transcript invades the DNA duplex, annealing to the template DNA and displacing the non-template DNA strand. Formation of R-loops is favoured by GC-rich sequences, by negative supercoiling and by impaired mRNA processing, and has been shown to interfere with replication fork progression [16].

Finally, the availability of resources can impact on replication fork progression and increase the chances of fork stalling. For example, replication fork speed is reduced when nucleotide pools are diminished or replication factors are limiting, as well as under conditions that inhibit nucleosome assembly on the newly synthesised DNA, for instance where histones are in short supply [17-19].

\section{Deregulated origin usage}

Strict regulation of the DNA replication program normally ensures that origins do not all fire simultaneously, but that sufficient origins are activated to complete replication of the entire genome during $\mathrm{S}$ phase. In fact, an excess of origins are licensed during each cell cycle, but many remain inactive unless nearby replication forks run into problems, in which case, these dormant origins may then be activated to offset local difficulties in replicating the DNA. It is also essential that any origin that is fired is activated once and only once in any given cell cycle, in order to prevent re-replication of sections of the genome. It is perhaps unsurprising then, that deregulation of this tightly controlled process can be problematic and a variety of inappropriate changes in origin usage are known to contribute to replication stress [20].

Although many more origins are licensed in each cell cycle than are usually required to complete DNA replication, reduced origin licensing can pose a problem for replicating cells. Fewer functional 
origins may mean that replication forks have to travel further, increasing the chance of stalling and, where fork stalls occur, fewer dormant origins will be available to compensate. Reduced origin usage will also increase the likelihood of cells reaching mitosis with incompletely replicated DNA. Where sister chromatids remain linked by such unreplicated regions, chromosome segregation will be impaired, leading to chromosome breakage and mitotic abnormalities [21]. As well as the potential difficulties resulting from insufficient origin usage, excessive origin firing may also be a significant source of replication stress as it can lead to exhaustion of replication substrates [22]. Increased replicon numbers will also increase the potential for collisions between the replication and transcriptional machinery [23]. Re-initiation of replication from origins that have fired already may cause problems typical of either origin under-use or origin over-use, depending on the frequency of such re-initiation events [20]. Infrequent re-initiation would give rise to isolated replication forks which would have to travel a long way before meeting a converging fork, whereas frequent reinitiation could lead to depletion of replication factors and increase the chances of collisions, either with the transcriptional machinery or, indeed, head-to-tail conflicts between replication forks as they follow each other along the same stretch of DNA template.

\section{The chromatin environment}

The chromatin context of DNA has a profound influence on its replication, affecting access to the replication machinery and necessitating the restoration of this chromatin structure once DNA synthesis is complete. As such, factors which affect this chromatin environment can be a further source of replication stress. For example, disruption of the epigenetic signature associated with latereplicating heterochromatin, notably tri-methylated histone $\mathrm{H} 3 \mathrm{~K} 9$, promotes chromatin accessibility, advancing replication timing and leading to re-replication [24, 25]. Misregulation of another epigenetic mark, tri-methylated histone H4K20, also results in re-replication, but in this case by increasing origin licencing [26]. The proper co-ordination of DNA synthesis with other aspects of chromatin biology, such as nucleosome repositioning, chromatin assembly on the newly synthesised DNA and the reconstitution of parental methylation patterns on the nascent DNA strand, are all important for efficient DNA replication and defects in each of these aspects can trigger replication stress [27-29].

\section{Oncogene-driven replication stress}

It is clear then that replication stress can arise in a variety of ways but a key issue, in terms of cancer development, is the question of how oncogene activation or tumour suppressor inactivation contributes to this process. In this respect, the answer is still far from clear cut with recent studies suggesting that different oncogenes may trigger replication stress through different mechanisms, and that individual oncogenes operate through multiple mechanisms.

A widespread consequence of oncogene activation or tumour suppressor loss is an overriding of the controls restricting the onset of $S$ phase [30-33]. This drives an unscheduled proliferative burst which is not necessarily matched by the metabolic capacity of the cell, and so replication stress is often a consequence of fork stalling due to an inadequate supply of necessary factors. The fact that this oncogene-induced replication stress phenotype can often be rescued by the addition of exogenous nucleosides suggests that nucleotide levels play a key role in this process [34]. Altered replication timing induced by oncogene activation will also increase the potential for conflicts between the 
replication and transcription machinery, as has been demonstrated for cyclin E overexpressing cells [23].

As well as advancing $\mathrm{S}$ phase entry, many oncogenes alter replication licensing and origin firing, with detrimental consequences for genome stability. Mammalian cells are normally prevented from entering $S$ phase with reduced origin licensing but a variety of oncogenes sensitise cells to licensing factor depletion, suggesting that they may compromise or override this licensing checkpoint, leading to replication stress [35]. Many oncogenes however, appear to cause replication stress through increased origin activity. Overexpression of oncoproteins such as cyclin E, RAS, MYC or HPV E6 and $E 7$, has been shown to reduce inter-origin distance, suggesting that origin firing is increased under these conditions $[10,23,31,34]$. In the case of MYC overexpression, this effect appears to be mediated through enhanced recruitment of initiation factors thereby increasing the number of active origins [36]. Moreover, upregulation of licensing factors is frequently observed in cancer cells in a manner that does not simply correlate with increased cell proliferation. For example, Cdc6 is upregulated in response to RAS, MOS and cyclin E overexpression, while inappropriate reloading of MCM proteins during $S$ phase has been observed in cells carrying oncogenic cyclin D1 mutations [9, $10,37,38]$. This misregulation of licensing factors supports re-replication from origins that have previously been activated, leading to DNA damage.

It is also clear that oncogene activation can trigger substantial changes in chromatin conformation which may, in turn, influence DNA accessibility, replication timing and genome stability. Significantly altered patterns of DNA methylation and histone modification in cancer cells are associated with impaired heterochromatin formation and misregulated gene silencing $[27,39]$.

\section{Consequences of replication stress}

\section{The cellular response to replication stress}

Regardless of the initial source of replication stress, stalled replication forks trigger a cellular response dependent on the protein kinase ATR (Figure 2). When replication forks stall, stretches of single-stranded DNA (ssDNA) are formed as the replicative helicase continues to unwind the DNA template ahead of the stalled DNA polymerase [40]. This primed ssDNA serves to recruit several replication stress response proteins, including ATR. Once activated, through its colocalisation with other factors at these ssDNA structures, ATR phosphorylates various effector targets to help stabilise the stalled fork structure and promote fork recovery. In addition, ATR-dependent phosphorylation of the downstream checkpoint kinase CHK1 triggers its release from chromatin to act on targets throughout the nucleus. This ATR-CHK1 pathway globally downregulates further origin firing until the replication stress has been removed, and prevents cells entering mitosis in the presence of unreplicated DNA [41].

Replication forks stabilised in this way can normally be restarted once the replication stress has been removed or, where stalling occurs at sites of unrepaired DNA damage, may be rescued through damage tolerance mechanisms. Damage tolerance pathways allow DNA lesions to be bypassed, either through recruitment of specialised translesion polymerases, that can replicate past damage that stalls the replicative polymerases, or by temporarily switching to an undamaged template e.g. the undamaged sister chromatid or the other nascent DNA strand following fork reversal [42]. These 
tolerance mechanisms, along with convergent replication following activation of dormant origins nearby, help to prevent prolonged fork stalling.

If however, the replication stress persists or if the ATR-dependent response is impaired, then fork collapse will most likely ensue. In these circumstances, it is widely believed that replisome components disengage from the fork preventing the resumption of replication [43, 44]. Fork collapse is associated with the formation of DNA double strand breaks (DSBs), which activate the DNA damage response kinase ATM. The precise origin of these DSBs is not yet fully understood. Singleended DSBs may form if a replication fork passes through a nicked DNA template (replication runoff), and may also reflect increased accessibility to endonucleases or passive breakage of susceptible ssDNA under conditions of prolonged stalling and replisome destabilisation (Figure 3) [12, 43]. Moreover, DSBs can arise during attempts to restore replication at such irretrievably stalled forks via recombination-based restart pathways. Reversed forks, 4-branched DNA structures resembling Holliday junctions, are subject to endonucleolytic cleavage, giving rise to one-ended DSBs. These reversed forks form more frequently and appear more susceptible to nucleolytic processing in the absence of ATR signalling $[45,46]$.

\section{Genome instability induced by replication stress}

Replication stress may lead to genome instability through a variety of mechanisms. At forks stalled by DNA damage, a variety of error-prone translesion synthesis polymerases can misincorporate nucleotides opposite damaged templates during lesion bypass, leading to nucleotide substitutions [47]. In contrast, lesion bypass through homologous recombination (HR) dependent template switching, utilising the sister chromatid as a template for repair, is usually considered to be a relatively error-free mechanism for recovery of stalled forks. However, HR can sometimes engage inappropriate sequences in non-allelic homologous recombination (NAHR), either by switching register in repeat regions or through recombination of homologous sequences dispersed through the genome, generating chromosome rearrangements with homology at the breakpoint junctions [48]. In addition, the stretches of ssDNA that are exposed during replication fork stalling are especially susceptible to DNA damage, leading to clustered base substitutions, particularly as a result of cytidine deaminase activity [49].

Following fork collapse, replication-associated DSBs can trigger genome instability through errorprone repair and replication-restart mechanisms. Unlike other DSBs, replication-induced DSBs at collapsed forks are single-ended, with no second end available for 'normal' DSB repair. Instead, these single-ended breaks may be repaired, and replication restored, through the HR-dependent process of break-induced replication (BIR) [50]. In BIR, the broken end invades a homologous sequence, usually the sister chromatid, re-establishing a replication fork (Figure 4). In the early stages, this replication is poorly processive and dependent on accessory factors which are dispensable for normal replication. During this period of low processivity, the extended DNA is frequently separated from, and then re-invades, the template, in a homology-driven manner. This cycle of extension, separation and re-invasion, perhaps reflecting a futile attempt to locate the other side of a two-ended DSB, is then followed by a switch to a more processive polymerase and a long length of DNA replication. Where the sister chromatid serves as a template for extension during BIR the genetic sequence should generally be conserved although, in yeast, it has been shown that this DNA synthesis step is, in fact, remarkably error-prone [51]. Moreover, strand invasion of the 
homologous chromosome, rather than the sister chromatid, will lead to loss of heterozygosity, while invasion at non-allelic sequences can lead to deletions, duplications or translocations $[48,50]$.

It has been proposed that a Rad51-independent BIR mechanism termed microhomology-mediated BIR (MMBIR) can also act at single-ended DSBs following fork collapse, and that this process may be key driver of non-recurrent copy number changes $[48,50]$. In contrast to homology-driven BIR, stretches of ssDNA with only a few bases of microhomology can support the template switch in MMBIR. This makes MMBIR very inexact, and can lead to deletions, inversions, amplifications or translocations, depending on the location of the template switch. Moreover, the cycle of template association, extension and separation characteristic of BIR, means that several of these changes may occur within a single repair event, producing complex rearrangements with microhomology at the breakpoint junctions, comparable to the copy number alterations commonly seen in cancer cells [52, 53]. MMBIR has been proposed as a possible mechanism for chromothripsis, in which numerous genomic rearrangements (several copy number changes and multiple breakpoints) are apparently acquired at a single chromosome in one catastrophic event [54]. It is conceivable that MMBIR is especially important for the rescue of collapsed forks under conditions of oncogene-induced replication stress, where the HR machinery may be overwhelmed by the level of fork stalling and collapse. In this respect, it is notable that cyclin E overexpression has been shown to induce copy number alterations through BIR repair of damaged forks, and that the breakpoint junctions of these rearrangements include microhomologies [55].

End-joining DSB repair mechanisms are considered to be much less important than HR for dealing with single-ended replication-induced DSBs, yet a body of data exists which implicates classical endjoining factors in the response to replication stress [56]. At present it remains unclear as to exactly how end-joining factors function in this response - whether they play a role in signalling, in regulating HR-dependent processes, or have a direct role in end-joining of replication-induced DSBs. The use of error-prone end-joining repair in this context would certainly represent a further potential source of genome instability, given the likelihood of joining the single broken end of one stalled fork to the broken DNA at a second stalled fork, either on the same chromosome or elsewhere in the genome, leading to chromosome rearrangements.

In addition to the problems it causes during $S$ phase, replication stress also triggers genome instability through its impact on chromosome segregation. Following replication stress, unreplicated regions of DNA or unresolved replication intermediates can persist into late $\mathrm{G} 2$ and mitosis, when they are cleaved by structure-specific nucleases [57]. If such structures are not fully resolved before the metaphase-anaphase transition, they form anaphase bridges linking the partially-replicated sister chromatids and restraining segregation. The tension exerted on these linked chromatids leads to chromosome breakage and uneven segregation of the chromosome arms. This is thought to be a particular problem at common fragile sites (CFSs), regions of the genome which are recognised as being especially prone to replication stress. CFSs often occur within very large genes in late replicating regions of the genome, where completion of replication prior to mitosis can be difficult to ensure. In some cases, this may be due to the extensive time required for transcription of these large genes, resulting in a temporal overlap with DNA replication and to conflicts between the two processes [58]. In other cases, it has been suggested that these regions are inherently difficult to replicate due to AT-rich regions of secondary structure which cause increased fork stalling $[59,60]$. 
In general, a paucity of origins around CFSs may prevent the rescue of stalled replication through dormant origins, and makes completion of replication prior to mitosis more difficult to achieve in these late-replicating regions $[60,61]$. It has also recently emerged that replication stress can lead to centrosome duplication leading to multipolar mitosis and aberrant chromosome segregation [62]. Moreover, aberrant mitoses, as a result of lagging chromosomes or chromosome fragments, frequently lead to micronuclei formation. The DNA contained within such micronuclei is especially prone to replication stress, due to the poor import of replication and repair factors, resulting in a spectrum of genomic rearrangements characteristic of chromothripsis [63, 64].

Finally, while chromatin structure and epigenetic modifications may influence replication stress, it is also likely that replication stress can have reciprocal effects on the chromatin environment and thereby on gene expression. For example, fork stalling interrupts histone recycling, perturbing the balance between new and old histones in association with chromatin assembly factors. Once replication resumes, this imbalance will result in the loss of histones bearing parental marks and an overrepresentation of new histones, including monomethylated $\mathrm{H} 3 \mathrm{~K} 9$, at the site of the fork stall [29]. Loss of parental histones alters the epigenetic profile of the newly synthesised DNA relative to parent template, while accumulation of methylated H3K9 promotes heterochromatin formation. These chromatin changes are likely to lead to local changes in gene expression as a consequence of replication stress.

\section{Replication stress in tumour development}

In recent years, high-throughput sequencing of cancer genomes has identified thousands of mutations in cancer tissues. These studies have revealed the large variation in mutation spectra between different cancers, and even between different samples within the same cancer type, highlighting the difficulty of determining which particular changes are important with respect to tumorigenesis. Interestingly, in early studies, relatively few targets were identified on a frequent basis, with the most common changes occurring predominantly in oncogenes or tumour suppressors. These findings lent support to the oncogene-induced replication stress model for cancer development, which suggested that unregulated proliferation may be the initial driving force for genome instability and tumorigenesis [5]. If correct, then cancer genomes might also be anticipated to bear patterns of genome instability associated with replication stress.

In this respect, it is interesting to note that several studies of recurrent copy number alterations in cancer tissues have identified changes in large gene sequences at a comparable level to those seen for oncogenes and tumour suppressors [65-67]. This is despite the fact that, in contrast to oncogenes/tumour suppressors, there is no apparent selective pressure for mutation of these large genes. Since long genes are known to be especially susceptible to replication stress, this has been taken as strong evidence to support the view that replication stress contributes to the generation of focal deletions in cancers [6]. In addition, surveys of non-recurrent copy number alterations in breast and ovarian cancers revealed the most prevalent type of alteration to be segmental head-to-tail tandem duplications with microhomology junctions [52, 53]. This type of change was recently demonstrated to occur as a consequence of BIR repair of collapsed forks, and so suggests that these mutations may have arisen as a result of fork collapse in breast and ovarian cancers [55]. 
Single nucleotide substitutions (SNS) have also been examined and have been found to occur more frequently in very large genes in a variety of cancer tissues, including colorectal cancers, head and neck cancers and melanomas [68]. Possible mechanistic explanations for this observed increase in SNSs in large genes invoke replication stress as a causative factor, either by increasing the prevalence of ssDNA in these regions, which would be more susceptible to DNA damage and less likely to undergo base repair, or by driving mutagenic BIR repair in regions prone to fork stalling and collapse. In breast cancer genomes, localized regions of hypermutation ("kataegis"), usually at the site of somatic rearrangements, have also been suggested to result from enzyme activity on ssDNA [69]. Finally, chromothripsis has been identified in various cancer genomes including, notably, up to $25 \%$ of bone cancer samples in one study [70]. Highly mutagenic MMBIR following fork stalling, and replication stress in micronuclei, have both been proposed to play a role in triggering chromothripsis $[54,64]$.

\section{Replication stress and cancer treatment}

It is clear from the previous discussion that replication stress is a key driver in the development and progression of many cancers. The transforming potential of this replication stress should initially be kept in check by a robust DNA damage response, but continued genome instability may eventually override this barrier, supporting cancer progression [11]. Whereas disruption of this DNA damage checkpoint can facilitate cancer development, a functional replication stress response may well remain important for the survival of these cancer cells, in the face of continued replicative stress. On this basis, several predictions can be made with regard to cancer cell behaviour.

Firstly, if they are already subject to high levels of oncogene-induced replication stress, cancer cells may be less able than normal cells to tolerate additional genomic insults. This should provide a therapeutic window for selective killing of cancer cells, through the application of exogenous genotoxic treatments to which they are more sensitive. In line with this fact, many therapies in current use do indeed cause replicative stress [71].

Secondly, cancer cells that are able to respond effectively to high levels of replication stress should have a survival advantage, which would most likely lead to poorer patient outcomes. There is some evidence to suggest that this is the case, since misregulation of replication-associated genes has been reported in a number of cancers and overexpression of a subset of these genes has been correlated with poor patient survival [72-74].

Thirdly, in cancers that have been induced by, and continue to experience high levels of oncogenedriven replicative stress, the ATR-CHK1 replication stress response will likely be crucial for cancer cell survival, and the abrogation of this response should allow for their selective elimination. At first glance this may seem counter-intuitive, since loss of ATR-CHK1 function enhances replication stressinduced genome instability. Indeed, mice which are haploinsuifficient for either kinase are tumourprone, presumably due to a relatively inefficient response to endogenous replicative stress levels, helping to drive tumorigenesis $[75,76]$. However, mice with more severely reduced levels of ATR are not cancer-prone, and it has been suggested that this is because a certain threshold of ATR activity is required to maintain the survival of transformed cells that are experiencing greater levels of replicative stress than normal tissues [77, 78]. This view is supported by studies demonstrating synthetic lethality between oncogene-induced replication stress and an impaired replication stress 
response. For example, siRNA knockdown of ATR proves lethal in a background of oncogenic RAS expression, while the development of MYC-induced lymphomas or pancreatic adenocarcinomas is completely prevented in mice with severely reduced ATR levels $[78,79]$. The ATR-CHK1 pathway is therefore emerging as a promising therapeutic target.

\section{Inhibitors of the ATR-CHK1 pathway}

In the last twenty years a range of CHK1 and ATR antagonists have been developed and tested as potential chemotherapeutic agents. Most early studies focused on the use of CHK1 inhibitors to potentiate the toxicity of existing genotoxic chemotherapies. The staurosporine analogue, UCN-01, was one of the first such inhibitors to be identified as a potential anticancer treatment, although it should be noted that this agent acts on numerous kinases and is not, in fact, selective for CHK1. Nevertheless, UCN-01 was shown to enhance the cytotoxicity of genotoxic drugs such as doxorubicin, cisplatin and irinotecan in preclinical trials [80-82]. More selective CHK1 inhibitors (LY2603618, PF0047736, MK-8776) and CHK1/2 dual inhibitors (AZD7762) were subsequently developed, and these also showed promise in preclinical studies as potentiating agents for genotoxic chemotherapeutics [83-87]. Unfortunately, despite some preliminary evidence of their anti-tumour activity, clinical trials with several of these compounds have revealed toxicity issues, while the development of MK-8776, which was not associated with cardiotoxicity, has, rather disappointingly, been terminated due to business reasons [88-90]. Other, newer CHK1 inhibitors are however, reported to be in development, including SAR-020106, CCT244747 and V158411, which have been shown to enhance the antitumour activity of irinotecan and gemcitabine in mouse xenograft models, and GDC0425 and GDC0575, currently in Phase I clinical trials in combination with gemcitabine (Table1) [91-93]. Several of these next generation CHK1 inhibitors have shown themselves to be relatively well tolerated when used in vivo, while CCT244747 is particularly notable as being the first CHK1 inhibitor to achieve effective bioavailability through oral administration [92].

As well as their role in enhancing the effect of other chemotherapy agents, CHK1 inhibitors are also being investigated for their potential as monotherapy. Monotherapy with CHK1 inhibitors has been reported to be ineffective in a variety of tumour models, and yet there is also ample evidence of their efficacy as a single agent. For example, CHK1 inhibitors are cytotoxic towards MYC-driven lymphoma cell lines and result in regression of MYC-induced lymphomas in a mouse model [78, 94]. Similar results have also been reported in the case of MYC-induced neuroblastomas and pancreatic cancers, as well as for melanoma cells which exhibit high levels of replication stress $[92,95,96]$. In contrast, K-RAS ${ }^{G 12 V}$-induced pancreatic adenocarcinomas, which do not exhibit elevated levels of replication stress, were unresponsive to treatment with CHK1 inhibitors [78]. These data provide strong support for the rationale outlined above, that an intact ATR-CHK1 response is fundamentally important to the survival of cancer cells with high levels of replicative stress, and that abolishing this response can be very effective in treating such cancers. Moreover, this reliance on ATR-CHK1 applies not only to oncogene-induced replication stress, but also to cells experiencing replication stress as a consequence of other defects in DNA metabolism. For example, cancer cells with defects in the Fanconi anaemia (FA) DNA repair pathway are hypersensitive to CHK1 inhibition, as compared with FA-proficient cells [97]. Ablation of ATR-CHK1 function is also reported to be synthetically lethal with loss of the single strand break repair factor XRCC1, and loss of the ERCC1-XPF nuclease, which functions in the repair of bulky DNA adducts, interstrand crosslinks and DSBs [98, 99]. 
The development of ATR inhibitors has lagged behind that of CHK1 inhibitors but has followed a similar trajectory [100]. The initial wave of compounds identified as having ATR inhibitory activity (Schisandrin B, NU6027, NVP-BEZ235), although capable of potentiating cancer cell sensitivity to a wide range of genotoxic treatments, suffered from a lack of selectivity or were required at relatively high concentrations to be effective [101-103]. High throughput screening has since identified several compounds that display much higher levels of selectivity and potency against ATR (Table 1) [104]. Of these, VE-821 was found to be capable of sensitising a wide range of different cancer cell lines to radio- and chemotherapy [105-108]. An analogue of this compound with increased potency and ATR selectivity, VX-970 (VE-822), has been shown to sensitise a pancreatic cancer xenograft model to ionising radiation and gemcitabine, while not increasing the sensitivity of normal cells to these treatments [109]. This compound was the first ATR inhibitor to enter clinical development, where it is currently undergoing assessment of its safety, tolerability, and pharmacokinetics, in combination with gemcitabine, cisplatin and etoposide, in subjects with advanced solid tumors. Similarly promising preclinical results have been obtained with another ATR inhibitor, AZD6738, which has been shown to possess significant anti-tumour activity when used in combination with radiotherapy, gemcitabine or cisplatin, or as a monotherapy in cells with compromised DNA repair pathways [110, 111]. Importantly, this compound seems to be well tolerated and suitable for oral dosing and it too is in Phase 1 clinical trials to establish its safety, both as a stand-alone treatment and in combination with radio- and chemotherapy.

\section{Conclusion}

Oncogene activation is widely recognised to trigger DNA replication stress, early in tumorigenesis, through dysregulation or disruption of the normal DNA replication program. This leads to genome instability as stalled and collapsed replication forks become subject to a variety of error-prone repair or replication restart processes. Accordingly, mutations characteristic of replication stress-induced genome instability have been identified in various cancer genomes. In order to withstand replicative stress, cells rely on the ATR-CHK1 pathway to stabilise stalled fork structures and promote recovery. Cancers cells that experience high levels of oncogene-induced replication stress are therefore heavily reliant on this checkpoint response and its abrogation should allow for their selective elimination. As such, the ATR-CHK1 pathway represents an attractive chemotherapeutic drug target, and a number of ATR and CHK1inhibitors have been developed in recent years. Several of these have proved effective in preclinical studies and are now in clinical trials to evaluate their effectiveness both as monotherapies and in combination with other agents.

\section{Future Perspective}

While the development of ATR and CHK1 inhibitors as cancer therapeutics shows considerable promise for the future, there are, of course, some key issues yet to be addressed. For instance, pharmacodynamic assessments of these compounds will need to give careful consideration to the order and timing of treatments when given in combination with other therapies, so as to maximise their effectiveness. When used alongside genotoxic agents that cause replication fork stalling, it may take some time for cells to enter S phase and encounter problems for which the ATR-CHK1 pathway becomes indispensable, and so, delayed administration or multiple dosing of the ATR/CHK1 inhibitor may be important to enhance cancer cell killing in this context [112]. 
Perhaps even more importantly, tumour profiling, to identify those patients most likely to benefit from ATR/CHK1 inhibitors, should increase the therapeutic index for these treatments. It is clear that certain tumour cells are more sensitive to killing by ATR/CHK1 inhibitors than others, either as combination therapy or as monotherapy, and this increased sensitivity seems to correlate with the degree of replication stress experienced [78, 112]. Although oncogene activation frequently leads to replication stress, individual oncogenes may do so through different mechanisms and to different extents in different cell contexts $[20,113]$. Reliable measures of replication stress will therefore be crucial for predicting how sensitive a particular tumour is likely to be to ATR-CHK1 inhibition. As such, the identification of validated biomarkers for enhanced replication stress is likely to be an important area of research in the next few years.

The most commonly used markers for replication stress in preclinical studies are readouts of ATR activation, by means of CHK1 or histone H2AX phosphorylation. However, H2AX is also phosphorylated, independently of ATR, in response to DNA DSBs and so is not a reliable marker for replicative stress. Similarly, only one of the two ATR phosphorylation sites of CHK1, Ser345, appears to be a specific marker for ATR activity, which may prove useful in a clinical context [102]. Other possible biomarkers for patient selection may be derived from monitoring the expression levels of replication stress response proteins. Upregulation of several replication-associated proteins has been correlated with poor patient outcomes in a variety of tumour types, suggesting that these cancer cells may have increased their resistance to replicative stress [72-74]. Inhibition of ATR-CHK1 function may prove to be a particularly effective way of overriding this adaptation in tumours exhibiting such replication stress 'signatures'.

Preclinical studies have also reported synergistic outcomes when ATR-CHK1 inhibition is combined with disruption of various DNA damage response (DDR) pathways [97-99, 108, 110]. This may be due to an increase in unrepaired damage in DDR-defective cells, leading to increased fork stalling and elevated levels of replication stress, or may be because these DDRs become essential for cell survival once forks collapse in the absence of ATR-CHK1 function. A number of DDR defects have thus far been identified as conferring sensitivity to ATR-CHK1 inhibition, and the advent of whole exome/genome sequencing should, in the future, provide the means of identifying patients/tumours with such defects. At present however, interactions between specific DDR defects and ATR-CHK1 dependence remain relatively poorly characterised and are not always unequivocal. For example, mutations of the MRE11-RAD50-NBS1 complex have been correlated with increased sensitivity to ATR-CHK1 inhibition, in both patients and cell lines, and yet, other studies have demonstrated an increased resistance to CHK1 inhibition in MRE11-deficient cells [110, 114, 115]. A more extensive characterisation of the biology behind these interactions is clearly required.

As well as intrinsic defects that sensitise to ATR-CHK1 inhibition, cancer cells may also acquire conditional DDR defects which are synergistic with such treatment, as reported for tumour cells under conditions of hypoxia [106]. Moreover, the development of novel pharmaceutical strategies for DDR inactivation means that it is becoming increasingly feasible to induce DDR defects, through treatment with specific DDR inhibitors, such as the PARP inhibiter olaparib. In this respect, it is notable that simultaneous targeting of CHK1 and the p38/MK2 global stress response pathway, required for prolonged checkpoint maintenance, results in strongly synergistic effects in KRAS- and BRAF-driven tumour cells [116]. A number of other drug combinations might also be envisaged to enhance ATR/CHK1 inhibitor utility, by enhancing levels of replication stress. For example, inhibition 
of the cell cycle regulator WEE1 triggers a burst of CDK activity which increases initiation of replication, leading to nucleotide depletion and fork stalling [22]. Accordingly, combined inhibition of WEE1 and CHK1 gives rise to synergistic antiproliferative effects, providing a rationale for further clinical investigation of these combined therapies [87, 117]. Several other inhibitors currently in clinical development have also been reported to cause replication stress and may, in future, be usefully exploited in combination with ATR-CHK1 inhibitors. These include MLN4924, a neddylation inhibitor which prevents the degradation of CDT1 leading to DNA re-replication, and OTS167, an inhibitor of the AMP-activated serine/threonine kinase MELK (maternal embryonic leucine zipper kinase) whose activity is required to reduce replication stress in glioblastoma cells [118-121]. Finally, in addition to the ATR or CHK1 kinases themselves, other aspects of the cellular response to replication stress can also be envisaged as potential therapeutic targets for future development. Factors involved in the recruitment and activation of ATR (e.g. ATRIP, TOPBP1, PRP19) are possible drug targets for the future, as are downstream-acting factors, such as proteins involved in recombinational repair and BIR.

We envisage that exploiting the dependence of many cancer cells on a functional replication stress response will be an important theme for cancer treatment in coming years. A number of inhibitors targeting the replication stress response are already being clinically evaluated and there is significant potential to extend this repertoire of treatments, through new developments and co-treatment strategies. The development of robust biomarkers to facilitate patient selection, ensuring that the most appropriate cohorts are chosen for treatment, may well be crucial to seeing good returns on this strategy, and should genuinely allow us to enter the era of personalised medicine.

\section{Executive summary}

\section{Causes of replication stress}

- Replication stress occurs when the tightly regulated program of DNA replication is disrupted, either by impediments to fork progression or through deregulated origin licensing/firing.

- Oncogene activation or tumour suppressor inactivation may lead to replication stress by overriding the controls restraining $S$ phase entry or by altering replication licensing and origin firing.

\section{Consequences of replication stress}

- When replication forks stall, an ATR-CHK1 dependent replication stress response helps to stabilise and restart stalled forks.

- In the case of persistent replication stress, or where ATR-CHK1 function is impaired, stalled forks can collapse, leading to DNA DSB formation.

- Replication stress can give rise to genetic changes through error-prone repair and replication-restart mechanisms, and can also cause problems during chromosome segregation leading to chromosome breakage and non-disjunction.

- Mutation signatures suggestive of replication stress have been identified in many cancer genomes.

\section{Replication stress and cancer treatment}


- Cancer cells that exhibit high levels of replication stress become dependent on the ATRCHK1 replication stress response for survival. This fact can be exploited for therapeutic purposes.

- $\quad$ CHK1 and ATR inhibitors show significant promise as cancer therapies, both as monotherapies and as potentiating agents for other drugs.

- The development of biomarkers to identify susceptible cancers will be important for the effective clinical application of these inhibitors. 


\section{References}

1. Hanahan D, Weinberg RA. Hallmarks of cancer: The next generation. Cell 144(5), 646-674 (2011).

2. Bartkova J, Horejsi $\mathrm{Z}$, Koed $\mathrm{K}$ et al. DNA damage response as a candidate anti-cancer barrier in early human tumorigenesis. Nature 434(7035), 864-870 (2005).

3. Gorgoulis VG, Vassiliou L-VF, Karakaidos P et al. Activation of the DNA damage checkpoint and genomic instability in human precancerous lesions. Nature 434(7035), 907-913 (2005).

4. Loeb LA. Mutator phenotype may be required for multistage carcinogenesis. Cancer Res. 51(12), 3075-3079 (1991).

5. Negrini S, Gorgoulis VG, Halazonetis TD. Genomic instability - an evolving hallmark of cancer. Nat. Rev. Mol. Cell Biol. 11(3), 220-228 (2010).

** Review of cancer genome sequencing data and how this is supportive of the oncogeneinduced DNA replication stress model of genome instability in cancer cells.

6. Macheret M, Halazonetis TD. DNA replication stress as a hallmark of cancer. Ann.Rev. Pathol. Mech. Dis. 10(1), 425-448 (2015).

7. Denko NC, Giaccia AJ, Stringer JR, Stambrook PJ. The human Ha-ras oncogene induces genomic instability in murine fibroblasts within one cell cycle. Proc. Natl. Acad. Sci. USA 91(11), 5124-5128 (1994).

8. Felsher DW, Bishop JM. Transient excess of MYC activity can elicit genomic instability and tumorigenesis. Proc. Natl. Acad. Sci. USA 96(7), 3940-3944 (1999).

9. Bartkova J, Rezaei $\mathrm{N}$, Liontos $\mathrm{M}$ et al. Oncogene-induced senescence is part of the tumorigenesis barrier imposed by DNA damage checkpoints. Nature 444(7119), 633-637 (2006).

10. Di Micco R, Fumagalli $M$, Cicalese $A$ et al. Oncogene-induced senescence is a DNA damage response triggered by DNA hyper-replication. Nature 444(7119), 638-642 (2006).

11. Halazonetis TD, Gorgoulis VG, Bartek J. An oncogene-induced DNA damage model for cancer development. Science 319(5868), 1352-1355 (2008).

12. Zeman MK, Cimprich KA. Causes and consequences of replication stress. Nat. Cell Biol. 16(1), 2-9 (2014).

13. Bochman ML, Paeschke K, Zakian VA. DNA secondary structures: Stability and function of gquadruplex structures. Nat. Rev. 13(11), 770-780 (2012).

14. Barlow JH, Faryabi Robert $b$, Callén $E$ et al. Identification of early replicating fragile sites that contribute to genome instability. Cell 152(3), 620-632 (2013).

15. Bermejo R, Lai Mong s, Foiani M. Preventing replication stress to maintain genome stability: Resolving conflicts between replication and transcription. Mol. Cell 45(6), 710-718 (2012).

16. Aguilera A, García-Muse T. R loops: From transcription byproducts to threats to genome stability. Mol. Cell 46(2), 115-124 (2012).

17. Anglana M, Apiou F, Bensimon A, Debatisse M. Dynamics of DNA replication in mammalian somatic cells: Nucleotide pool modulates origin choice and interorigin spacing. Cell 114(3), 385-394 (2003).

18. Mejlvang J, Feng $\mathrm{Y}$, Alabert $\mathrm{C}$ et al. New histone supply regulates replication fork speed and PCNA unloading. J. Cell Biol. 204(1), 29-43 (2014).

19. Toledo LI, Altmeyer M, Rask MB et al. ATR prohibits replication catastrophe by preventing global exhaustion of RPA. Cell 155(5), 1088-1103 (2013).

20. Hills SA, Diffley JFX. DNA replication and oncogene-induced replicative stress. Curr.Biol. 4(10), R435-R444 (2014).

* Reviews how deregulation of DNA replication can promote genome instability 
21. Burrell RA, Mcclelland SE, Endesfelder $\mathrm{D}$ et al. Replication stress links structural and numerical cancer chromosomal instability. Nature 494(7438), 492-496 (2013).

22. Beck H, Nahse-Kumpf V, Larsen MSY et al. Cyclin-dependent kinase suppression by WEE1 kinase protects the genome through control of replication initiation and nucleotide consumption. Mol. Cell. Biol. 32(20), 4226-4236 (2012).

23. Jones RM, Mortusewicz $\mathrm{O}$, Afzal I et al. Increased replication initiation and conflicts with transcription underlie cyclin E-induced replication stress. Oncogene 32(32), 3744-3753 (2013).

24. Black JC, Allen A, Van Rechem $C$ et al. Conserved antagonism between JMJD2A/KDM4A and HP1gamma during cell cycle progression. Mol. Cell 40(5), 736-748 (2010).

25. Black JC, Manning AL, Van Rechem C et al. KDM4A lysine demethylase induces site-specific copy gain and rereplication of regions amplified in tumors. Cell 154(3), 541-555 (2013).

26. Beck DB, Burton A, Oda H, Ziegler-Birling C, Torres-Padilla ME, Reinberg D. The role of PRSet7 in replication licensing depends on Suv4-20h. Genes Dev. 26(23), 2580-2589 (2012).

27. Fraga MF, Ballestar E, Villar-Garea A et al. Loss of acetylation at Lys16 and trimethylation at Lys20 of histone $\mathrm{H} 4$ is a common hallmark of human cancer. Nature Genet. 37(4), 391-400 (2005).

28. Unterberger A, Andrews SD, Weaver IC, Szyf M. DNA methyltransferase 1 knockdown activates a replication stress checkpoint. Mol. Cell. Biol. 26(20), 7575-7586 (2006).

29. Khurana S, Oberdoerffer P. Replication stress: A lifetime of epigenetic change. Genes 6(3), 858-877 (2015).

30. Almasan A, Yin Y, Kelly RE et al. Deficiency of retinoblastoma protein leads to inappropriate S-phase entry, activation of E2f-responsive genes, and apoptosis. Proc. Natl. Acad. Sci USA 92(12), 5436-5440 (1995).

31. Dominguez-Sola D, Ying CY, Grandori C et al. Non-transcriptional control of DNA replication by c-Myc. Nature 448(7152), 445-451 (2007).

32. Liu JJ, Chao JR, Jiang MC, Ng SY, Yen JJ, Yang-Yen HF. Ras transformation results in an elevated level of cyclin D1 and acceleration of G1 progression in NIH 3T3 cells. Mol. Cell. Biol. 15(7), 3654-3663 (1995).

33. Sunters A, Thomas DP, Yeudall WA, Grigoriadis AE. Accelerated cell cycle progression in osteoblasts overexpressing the c-fos proto-oncogene: Induction of cyclin A and enhanced CDK2 activity. J. Biol.Chem. 279(11), 9882-9891 (2004).

34. Bester Assaf c, Roniger $M$, Oren Yifat s et al. Nucleotide deficiency promotes genomic instability in early stages of cancer development. Cell 145(3), 435-446 (2011).

35. Zimmerman KM, Jones RM, Petermann E, Jeggo PA. Diminished origin-licensing capacity specifically sensitizes tumor cells to replication stress. Mol.Cancer Res. 11(4), 370-380 (2013).

36. Srinivasan SV, Dominguez-Sola D, Wang LC, Hyrien O, Gautier J. Cdc45 is a critical effector of Myc-dependent DNA replication stress. Cell Rep. 3(5), 1629-1639 (2013).

37. Aggarwal P, Lessie MD, Lin DI et al. Nuclear accumulation of cyclin D1 during $S$ phase inhibits Cul4-dependent Cdt1 proteolysis and triggers p53-dependent DNA rereplication. Genes Dev. 21(22), 2908-2922 (2007).

38. Mailand N, Diffley JFX. CDKs promote DNA replication origin licensing in human cells by protecting Cdc6 from APC/C-dependent proteolysis. Cell 122(6), 915-926 (2005).

39. Sharma S, Kelly TK, Jones PA. Epigenetics in cancer. Carcinogenesis 31(1), 27-36 (2010).

40. Byun TS, Pacek M, Yee MC, Walter JC, Cimprich KA. Functional uncoupling of MCM helicase and DNA polymerase activities activates the ATR-dependent checkpoint. Genes Dev. 19(9), 1040-1052 (2005).

41. Cimprich KA, Cortez D. ATR: An essential regulator of genome integrity. Nat. Rev. Mol. Cell Biol. 9(8), 616-627 (2008). 
42. Chang DJ, Cimprich KA. DNA damage tolerance: When it's OK to make mistakes. Nat. Chem. Biol. 5(2), 82-90 (2009).

43. Ragland RL, Patel S, Rivard RS et al. RNF4 and PLK1 are required for replication fork collapse in ATR-deficient cells. Genes Dev. 27(20), 2259-2273 (2013).

44. Roseaulin LC, Noguchi C, Martinez E, Ziegler MA, Toda T, Noguchi E. Coordinated degradation of replisome components ensures genome stability upon replication stress in the absence of the replication fork protection complex. PLoS Genet 9(1), e1003213 (2013).

45. Couch FB, Bansbach CE, Driscoll $\mathrm{R}$ et al. ATR phosphorylates SMARCAL1 to prevent replication fork collapse. Genes Dev. 27(14), 1610-1623 (2013).

46. Sorensen CS, Syljuasen RG. Safeguarding genome integrity: The checkpoint kinases ATR, CHK1 and WEE1 restrain CDK activity during normal DNA replication. Nucl. Acids Res. 40(2), 477-486 (2012).

47. Sale JE. Translesion DNA synthesis and mutagenesis in eukaryotes. CSH Perspect. Biol. 5(3), (2013).

48. Hastings PJ, Lupski JR, Rosenberg SM, Ira G. Mechanisms of change in gene copy number. Nat. Rev .Genet. 10(8), 551-564 (2009).

49. Roberts SA, Sterling J, Thompson C et al. Clustered mutations in yeast and in human cancers can arise from damaged long single-strand DNA regions. Mol. Cell 46(4), 424-435 (2012).

50. Hastings PJ, Ira G, Lupski JR. A microhomology-mediated break-induced replication model for the origin of human copy number variation. PLoS Genet 5(1), e1000327 (2009).

51. Hicks WM, Kim M, Haber JE. Increased mutagenesis and unique mutation signature associated with mitotic gene conversion. Science 329(5987), 82-85 (2010).

52. Stephens PJ, Mcbride DJ, Lin ML et al. Complex landscapes of somatic rearrangement in human breast cancer genomes. Nature 462(7276), 1005-1010 (2009).

53. Mcbride DJ, Etemadmoghadam D, Cooke SL et al. Tandem duplication of chromosomal segments is common in ovarian and breast cancer genomes. J. Path. 227(4), 446-455 (2012).

54. Liu PF, Erez A, Nagamani SCS et al. Chromosome catastrophes involve replication mechanisms generating complex genomic rearrangements. Cell 146(6), 888-902 (2011).

55. Costantino L, Sotiriou SK, Rantala JK et al. Break-induced replication repair of damaged forks induces genomic duplications in human cells. Science 343(6166), 88-91 (2014).

\section{** First demonstration that BIR occurs in response to replication stress in mammalian cells.}

56. Allen C, Ashley AK, Hromas R, Nickoloff JA. More forks on the road to replication stress recovery. J. Mol. Cell Biol. 3(1), 4-12 (2011).

57. Naim V, Wilhelm T, Debatisse M, Rosselli F. ERCC1 and MUS81-EME1 promote sister chromatid separation by processing late replication intermediates at common fragile sites during mitosis. Nat. Cell Biol. 15(8), 1008-1015 (2013).

58. Helmrich A, Ballarino M, Nudler E, Tora L. Transcription-replication encounters, consequences and genomic instability. Nat. Struct. Mol. Biol. 20(4), 412-418 (2013).

59. Burrow AA, Marullo A, Holder LR, Wang YH. Secondary structure formation and DNA instability at fragile site FRA16B. Nucl. Acids Res. 38(9), 2865-2877 (2010).

60. Ozeri-Galai E, Lebofsky R, Rahat A, Bester AC, Bensimon A, Kerem B. Failure of origin activation in response to fork stalling leads to chromosomal instability at fragile sites. Mol. Cell 43(1), 122-131 (2011).

61. Letessier A, Birnbaum D, Debatisse $M$, Chaffanet $M$. Does poverty in replication initiation sites render certain genome regions fragile? Med Sci 27(8-9), 707-709 (2011).

62. Wilhelm T, Magdalou I, Barascu A, Techer H, Debatisse M, Lopez BS. Spontaneous slow replication fork progression elicits mitosis alterations in homologous recombinationdeficient mammalian cells. Proc. Natl. Acad. Sci. USA 111(2), 763-768 (2014). 
63. Crasta K, Ganem NJ, Dagher R et al. DNA breaks and chromosome pulverization from errors in mitosis. Nature 482(7383), 53-58 (2012).

64. Zhang CZ, Spektor A, Cornils $\mathrm{H}$ et al. Chromothripsis from DNA damage in micronuclei. Nature 522(7555), 179-184 (2015).

65. Beroukhim R, Mermel $\mathrm{CH}$, Porter $\mathrm{D}$ et al. The landscape of somatic copy-number alteration across human cancers. Nature 463(7283), 899-905 (2010).

66. Bignell GR, Greenman CD, Davies $\mathrm{H}$ et al. Signatures of mutation and selection in the cancer genome. Nature 463(7283), 893-898 (2010).

67. Zack TI, Schumacher SE, Carter SL et al. Pan-cancer patterns of somatic copy number alteration. Nat. Genet 45(10), 1134-1140 (2013).

68. Nikolaev SI, Rimoldi D, Iseli $C$ et al. Exome sequencing identifies recurrent somatic MAP2K1 and MAP2K2 mutations in melanoma. Nat. Genet. 44(2), 133-139 (2012).

69. Nik-Zainal S, Alexandrov Ludmil b, Wedge David c et al. Mutational processes molding the genomes of 21 breast cancers. Cell 149(5), 979-993 (2012).

70. Stephens PJ, Greenman CD, Fu BY et al. Massive genomic rearrangement acquired in a single catastrophic event during cancer development. Cell 144(1), 27-40 (2011).

71. Lord CJ, Ashworth A. The DNA damage response and cancer therapy. Nature 481(7381), 287294 (2012).

72. Allera-Moreau C, Rouquette I, Lepage B et al. DNA replication stress response involving PLK1, CDC6, POLQ, RAD51 and CLASPIN upregulation prognoses the outcome of early/midstage non-small cell lung cancer patients. Oncogenesis 1 (10) (2012).

73. Lau KM, Chan QKY, Pang JCS et al. Minichromosome maintenance proteins 2, 3 and 7 in medulloblastoma: Overexpression and involvement in regulation of cell migration and invasion. Oncogene 29(40), 5475-5489 (2010).

74. Pillaire MJ, Selves J, Gordien K et al. A 'DNA replication' signature of progression and negative outcome in colorectal cancer (vol 29, pg 876, 2009). Oncogene 29(14), 2160-2160 (2010).

75. Brown EJ, Baltimore D. ATR disruption leads to chromosomal fragmentation and early embryonic lethality. Genes Dev. 14, 397-402 (2000).

76. Lam MH, Liu QH, Elledge SJ, Rosen JM. CHK1 is haploinsufficient for multiple functions critical to tumor suppression. Cancer Cell 6(1), 45-59 (2004).

77. Murga M, Bunting S, Montana MF et al. A mouse model of ATR-Seckel shows embryonic replicative stress and accelerated aging. Nat. Genet. 41(8), 891-898 (2009).

78. Murga M, Campaner S, Lopez-Contreras AJ et al. Exploiting oncogene-induced replicative stress for the selective killing of MYC-driven tumors. Nat. Struct. Mol. Biol. 18(12), 13311335 (2011).

* Demonstrated synthetic lethality of ATR-CHK1 ablation in combination with high levels of oncogene-induced replicative stress.

79. Gilad O, Nabet BY, Ragland RL et al. Combining ATR suppression with oncogenic Ras synergistically increases genomic instability, causing synthetic lethality or tumorigenesis in a dosage-dependent manner. Cancer Res. 70(23), 9693-9702 (2010).

80. Bunch R, Eastman A. 7-hydroxystaurosporine (UCN-01) causes redistribution of proliferating cell nuclear antigen and abrogates cisplatin-induced S-phase arrest in Chinese hamster ovary cells. Cell Growth Differ. 8(7), 779-788 (1997).

81. Luo Y, Rockow-Magnone SK, Joseph MK et al. Abrogation of G2 checkpoint specifically sensitize p53 defective cells to cancer chemotherapeutic agents. Anticancer Res. 21(1A), 2328 (2001).

82. Tse AN, Schwartz GK. Potentiation of cytotoxicity of topoisomerase I poison by concurrent and sequential treatment with the checkpoint inhibitor UCN-01 involves disparate 
mechanisms resulting in either p53-independent clonogenic suppression or p53-dependent mitotic catastrophe. Cancer Res. 64(18), 6635-6644 (2004).

83. Blasina A, Hallin J, Chen EH et al. Breaching the DNA damage checkpoint via PF-00477736, a novel small-molecule inhibitor of checkpoint kinase 1. Mol. Cancer Ther. 7(8), 2394-2404 (2008).

84. King C, Diaz H, Barnard D et al. Characterization and preclinical development of LY2603618: A selective and potent Chk1 inhibitor. Invest. New Drugs 32(2), 213-226 (2014).

85. Landau HJ, Mcneely SC, Nair JS et al. The checkpoint kinase inhibitor AZD7762 potentiates chemotherapy-induced apoptosis of p53-mutated multiple myeloma cells. Mol. Cancer Ther. 11(8), 1781-1788 (2012).

86. Montano R, Thompson R, Chung I, Hou H, Khan N, Eastman A. Sensitization of human cancer cells to gemcitabine by the Chk1 inhibitor MK-8776: Cell cycle perturbation and impact of administration schedule in vitro and in vivo. BMC Cancer 13, 604-604 (2013).

87. Chaudhuri L, Vincelette ND, Koh BD et al. CHK1 and WEE1 inhibition combine synergistically to enhance therapeutic efficacy in acute myeloid leukemia ex vivo. Haematologica 99(4), 688-696 (2014).

88. Daud Al, Ashworth MT, Strosberg J et al. Phase I dose-escalation trial of checkpoint kinase 1 inhibitor MK-8776 as monotherapy and in combination with gemcitabine in patients with advanced solid tumors. J. Clin. Oncol. 33(9), 1060-1066 (2015).

89. Mcneely S, Beckmann R, Lin AKB. Chek again: Revisiting the development of CHK1 inhibitors for cancer therapy. Pharmacol. Ther. 142(1), 1-10 (2014).

\section{*Extensive review of CHK1 inhibitor development}

90. Sausville E, Lorusso P, Carducci $M$ et al. Phase I dose-escalation study of AZD7762, a checkpoint kinase inhibitor, in combination with gemcitabine in US patients with advanced solid tumors. Cancer Chemother. Pharmacol.73(3), 539-549 (2014).

91. Walton MI, Eve PD, Hayes A et al. The preclinical pharmacology and therapeutic activity of the novel CHK1 inhibitor SAR-020106. Mol. Cancer Ther 9(1), 89-100 (2010).

92. Walton MI, Eve PD, Hayes A et al. CCT244747 is a novel potent and selective CHK1 inhibitor with oral efficacy alone and in combination with genotoxic anticancer drugs. Clin.Cancer Res. 18(20), 5650-5661 (2012).

93. Massey AJ, Stokes $\mathrm{S}$, Browne $\mathrm{H}$ et al. Identification of novel, in vivo active CHK1 inhibitors utilizing structure guided drug design. Oncotarget, (2015).

94. Ferrao PT, Bukczynska EP, Johnstone RW, Mcarthur GA. Efficacy of CHK inhibitors as single agents in MYC-driven lymphoma cells. Oncogene 31(13), 1661-1672 (2012).

95. Brooks K, Oakes V, Edwards B et al. A potent Chk1 inhibitor is selectively cytotoxic in melanomas with high levels of replicative stress. Oncogene 32(6), 788-796 (2013).

96. Cole KA, Huggins J, Laquaglia $M$ et al. RNAi screen of the protein kinome identifies checkpoint kinase 1 (CHK1) as a therapeutic target in neuroblastoma. Proc. Natl. Acad. Sci. USA 108(8), 3336-3341 (2011).

97. Chen CC, Kennedy RD, Sidi S, Look AT, D'andrea A. CHK1 inhibition as a strategy for targeting fanconi anemia (FA) DNA repair pathway deficient tumors. Mol. Cancer 8, (2009).

98. Mohni KN, Kavanaugh GM, Cortez D. ATR pathway inhibition is synthetically lethal in cancer cells with ERCC1 deficiency. Cancer Res. 74(10), 2835-2845 (2014).

99. Sultana $\mathrm{R}, \mathrm{Abdel}-\mathrm{Fatah} \mathrm{T}$, Perry $\mathrm{C}$ et al. Ataxia telangiectasia mutated and rad3 related (ATR) protein kinase inhibition is synthetically lethal in XRCC1 deficient ovarian cancer cells. PloS One 8(2), (2013).

100. Weber AM, Ryan AJ. ATM and ATR as therapeutic targets in cancer. Pharmacol. Ther. 149, 124-138 (2015).

*Extensive review of ATR inhibitor development 
101. Nishida $H$, Tatewaki N, Nakajima $Y$ et al. Inhibition of ATR protein kinase activity by schisandrin B in DNA damage response. Nucl. Acids Res. 37(17), 5678-5689 (2009).

102. Peasland A, Wang LZ, Rowling $E$ et al. Identification and evaluation of a potent novel ATR inhibitor, NU6027, in breast and ovarian cancer cell lines. Br. J. Cancer 105(3), 372-381 (2011).

103. Toledo LI, Murga M, Zur R et al. A cell-based screen identifies ATR inhibitors with synthetic lethal properties for cancer-associated mutations. Nat. Struct. Mol. Biol. 18(6), 721-727 (2011).

104. Charrier JD, Durrant SJ, Golec JMC et al. Discovery of potent and selective inhibitors of ataxia telangiectasia mutated and rad3 related (ATR) protein kinase as potential anticancer agents. J. Med. Chem. 54(7), 2320-2330 (2011).

105. Huntoon CJ, Flatten KS, Hendrickson AEW et al. ATR inhibition broadly sensitizes ovarian cancer cells to chemotherapy independent of BRCA status. Cancer Res. 73(12), 3683-3691 (2013).

106. Pires IM, Olcina MM, Anbalagan S et al. Targeting radiation-resistant hypoxic tumour cells through ATR inhibition. Br. J. Cancer 107(2), 291-299 (2012).

107. Prevo R, Fokas E, Reaper PM et al. The novel ATR inhibitor VE-821 increases sensitivity of pancreatic cancer cells to radiation and chemotherapy. Cancer Biol. Ther. 13(11), 1072-1081 (2012).

108. Reaper PM, Griffiths MR, Long JM et al. Selective killing of ATM- or p53-deficient cancer cells through inhibition of ATR. Nat. Chem. Biol. 7(7), 428-430 (2011).

109. Fokas E, Prevo R, Pollard JR et al. Targeting ATR in vivo using the novel inhibitor VE-822 results in selective sensitization of pancreatic tumors to radiation. Cell Death Dis 3, e441 (2012).

110. Foote KM, Blades K, Cronin A et al. Discovery of 4-\{4-[(3r)-3-methylmorpholin-4-yl]-6[1(methylsulfonyl)cyclopropyl]pyrimidin-2-yl\}-1h-indole (AZ20): A potent and selective inhibitor of ATR protein kinase with monotherapy in vivo antitumor activity. J. Med. Chem.56(5), 2125-2138 (2013).

111. Guichard SM, Brown E, Odedra R et al. The pre-clinical in vitro and in vivo activity of AZD6738: A potent and selective inhibitor of ATR kinase. Cancer Res. 73(8), (2013).

112. Montano R, Chung I, Garner KM, Parry D, Eastman A. Preclinical development of the novel Chk1 inhibitor SCH900776 in combination with DNA-damaging agents and antimetabolites. Mol. Cancer Ther. 11(2), 427-438 (2012).

113. Maya-Mendoza A, Ostrakova J, Kosar M et al. Myc and Ras oncogenes engage different energy metabolism programs and evoke distinct patterns of oxidative and DNA replication stress. Mol. Oncol. 9(3), 601-616 (2015).

114. Al-Ahmadie $\mathrm{H}$, lyer $\mathrm{G}$, Hohl $\mathrm{M}$ et al. Synthetic lethality in ATM-deficient RAD50-mutant tumors underlies outlier response to cancer therapy. Cancer Discov 4(9), 1014-1021 (2014).

115. Thompson R, Montano R, Eastman A. The Mre11 nuclease is critical for the sensitivity of cells to Chk1 inhibition. PloS One 7(8), (2012).

116. Dietlein $\mathrm{F}$, Kalb B, Jokic $\mathrm{M}$ et al. A synergistic interaction between Chk1- and MMK2 inhibitors in KRAS-mutant cancer. Cell 162(1), 146-159 (2015).

117. Davies KD, Cable PL, Garrus JE et al. Chk1 inhibition and Wee1 inhibition combine synergistically to impede cellular proliferation. Cancer Biol. Ther. 12(9), 788-796 (2011).

118. Chung SY, Suzuki H, Miyamoto $T$ et al. Development of an orally-administrative MELKtargeting inhibitor that suppresses the growth of various types of human cancer. Oncotarget 3(12), 1629-1640 (2012).

119. Kig C, Beullens M, Beke L et al. Maternal embryonic leucine zipper kinase (MELK) reduces replication stress in glioblastoma cells. J. Biol. Chem. 288(33), 24200-24212 (2013). 
120. Lin JJ, Milhollen MA, Smith PG, Narayanan U, Dutta A. NEDD8-targeting drug MLN4924 elicits DNA rereplication by stabilizing Cdt1 in S phase, triggering checkpoint activation, apoptosis, and senescence in cancer cells. Cancer Res. 70(24), 10310-10320 (2010).

121. Soucy TA, Smith PG, Milhollen MA et al. An inhibitor of NEDD8-activating enzyme as a new approach to treat cancer. Nature 458(7239), 732-736 (2009). 


\section{Figure legends}

\section{Figure 1. Oncogene-induced DNA replication stress model for cancer progression}

Increased cellular proliferation, as a consequence of oncogene activation, is an early event in cancer development which leads to DNA replication stress and genome instability. In precancerous lesions, the DNA damage response (DDR) helps to restrain cancer progression by triggering cell death, but inactivation of this damage checkpoint allows cells to escape from apoptosis or senescence and complete the transition from precancerous lesion to cancer.

\section{Figure 2. The ATR-dependent replication stress response}

At stalled forks, stretches of ssDNA, bound by the single-stranded DNA binding protein RPA, are generated by uncoupling of the replicative helicase and polymerase. The checkpoint protein complexes, RAD9-RAD1-HUS1 (9-1-1) and ATR-ATRIP, bind to the junction of the 5'primer and this SSDNA. TOPBP1 is then recruited through its binding to RAD9. TOPBP1 interaction activates the ATR kinase, leading to phosphorylation of CHK1 and other effectors. ATR- and CHK1-dependent phosphorylation events serve to maintain the stability of the replisome and promote fork restart, to inhibit late origin firing and delay cell cycle progression.

\section{Figure 3. Formation of replication-dependent DNA double strand breaks}

Single-ended DNA double strand breaks (DSBs) may result from fork collapse through a variety of possible mechanisms, including replication run-off at single-strand nicks ahead of the replication fork, passive breakage or nucleolytic cleavage of persistent ssDNA at forks stalled by a DNA lesion ( $\Delta$ ) or nuclease digestion of a reversed fork structure.

\section{Figure 4. Repair of a collapsed fork by break induced replication}

Repair of a single-ended DSB (A) and re-establishment of replication at a collapsed fork can be achieved through break induced replication (BIR). BIR is initiated by resection of the 5' strand (B), generating a 3' overhang which can invade a homologous template (C) to form a replication fork which extends both leading and lagging strands through low processivity polymerisation (D). The 3' end separates from the template (E) and then reinvades to establish another replication fork (F). This process can occur multiple times before a more processive fork is established (G) and replication continues over a substantial distance $(\mathrm{H})$. 
Table 1. CHK1 and ATR inhibitors currently in development (preclinical and clinical studies)

\begin{tabular}{|c|c|c|c|}
\hline Compound & Target & Notable clinical or preclinical data & References \\
\hline SAR-020106 & CHK1 & $\begin{array}{l}\text { Effective in in vivo preclinical studies in combination with } \\
\text { gemcitabine and irinotecan }\end{array}$ & [91] \\
\hline CCT244747 & CHK1 & $\begin{array}{l}\text { Effective in preclinical studies as a single agent in MYCN- } \\
\text { driven retinoblastoma model or in combination with } \\
\text { gemcitabine or irinotecan. Can be administered orally. }\end{array}$ & {$[92]$} \\
\hline V158411 & CHK1 & $\begin{array}{l}\text { Effective against multiple p53-deficient tumours in } \\
\text { combination with irinotecan in preclinical studies. No } \\
\text { additional systemic toxicity observed in vivo. }\end{array}$ & [93] \\
\hline GDC0425/ GDC0575 & CHK1 & In Phase 1 clinical trials in combination with gemcitabine & \begin{tabular}{|l|} 
NCT01359696/ \\
NCT01564251 \\
\end{tabular} \\
\hline VE-821 & ATR & $\begin{array}{l}\text { Sensitises pancreatic tumours to ionising radiation and } \\
\text { gemcitabine in xenograft model. }\end{array}$ & [107] \\
\hline VX-970 & ATR & $\begin{array}{l}\text { Analogue of VE- } 821 \text {. In Phase } 1 \text { trial in combination with } \\
\text { gemcitabine, cisplatin and etoposide. }\end{array}$ & NCT02157792 \\
\hline AZD6738 & ATR & $\begin{array}{l}\text { Well tolerated and suitable for oral administration. } \\
\text { Currently in Phase } 1 \text { clinical trials as monotherapy and in } \\
\text { combination with radio and chemotherapy }\end{array}$ & $\begin{array}{l}\text { NCT02223923, } \\
\text { NCT01955668, } \\
\text { NCT02264678 } \\
{[110]} \\
{[111]}\end{array}$ \\
\hline
\end{tabular}




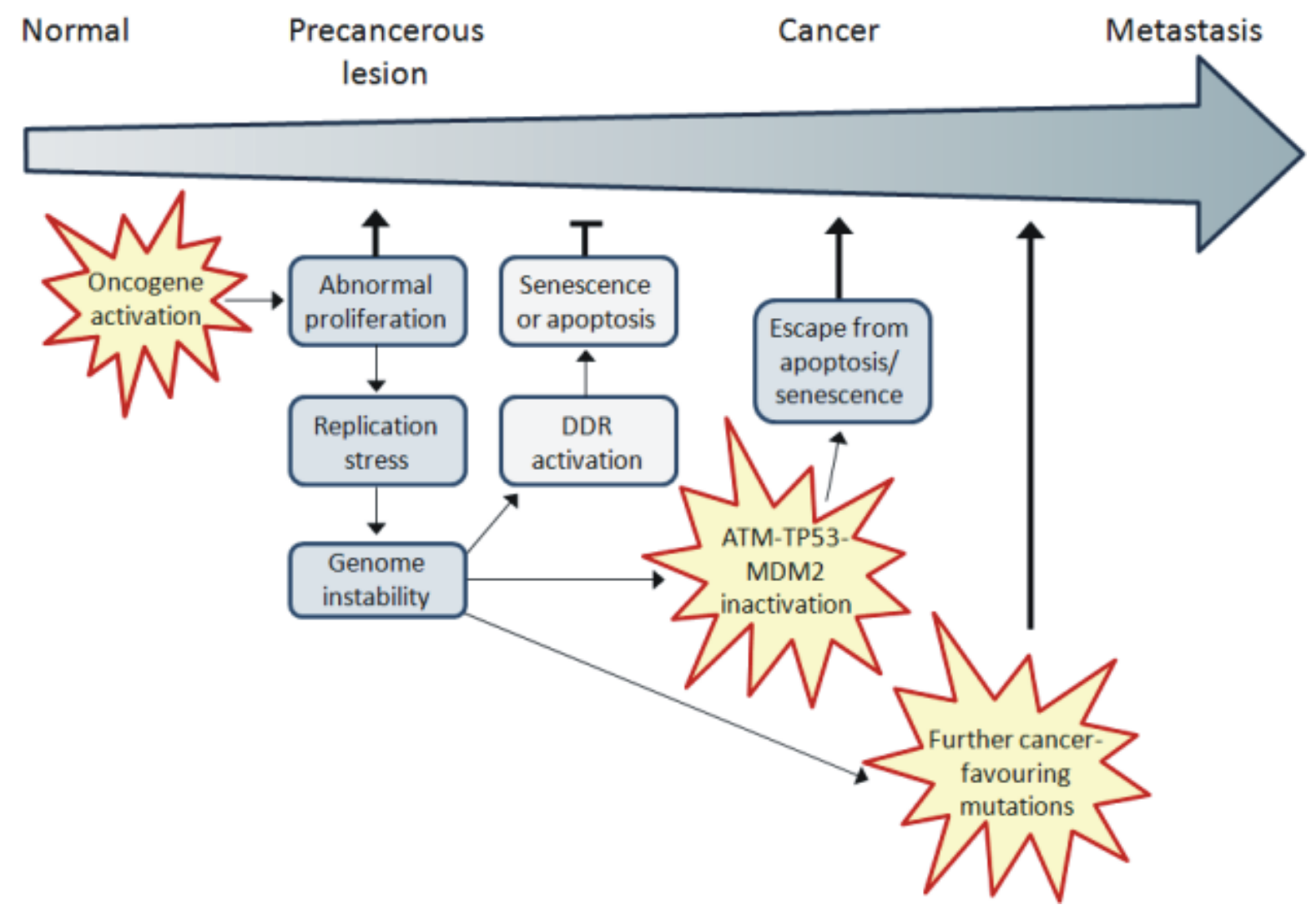

Figure 1. Oncogene-induced DNA replication stress model for cancer progression 


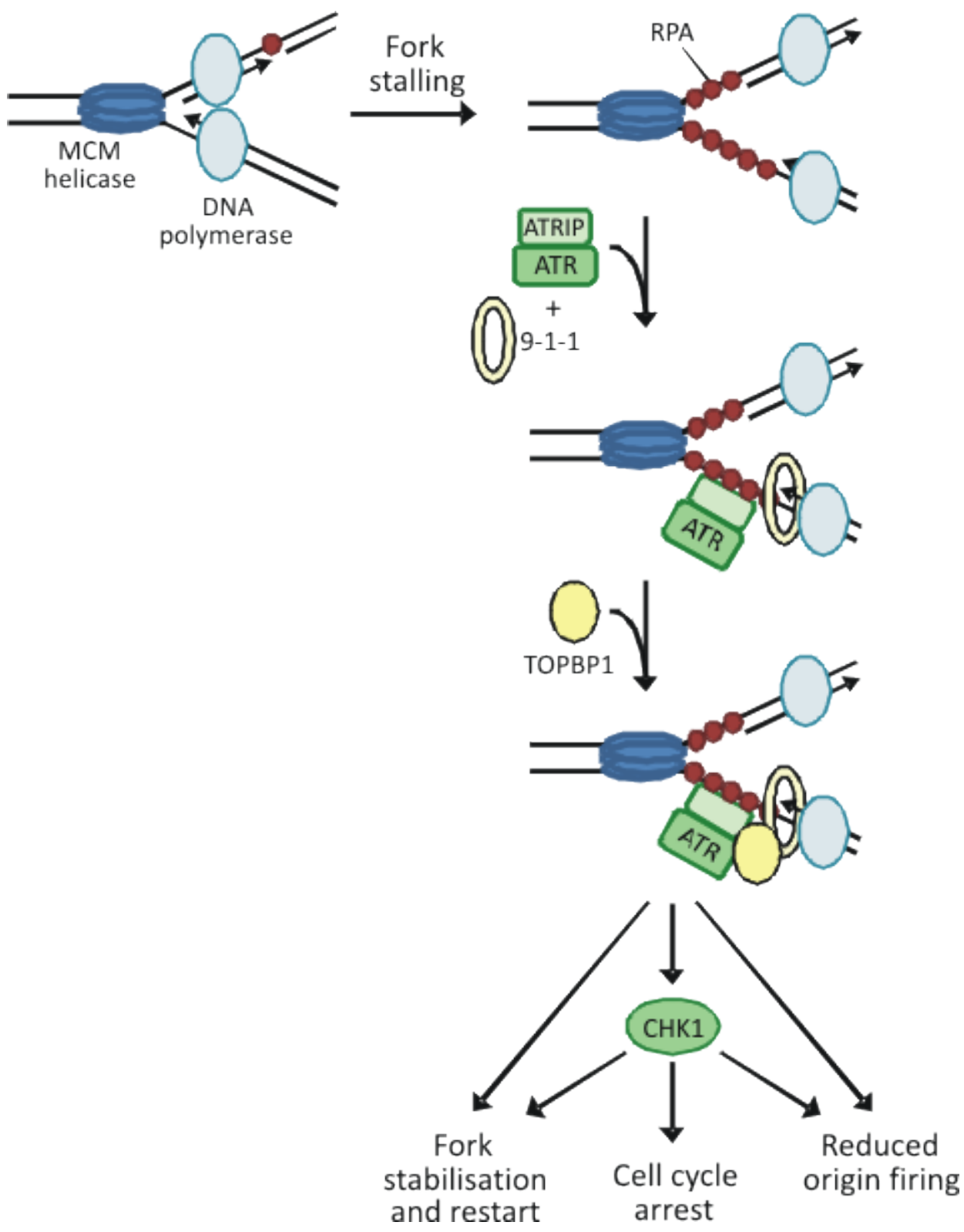

Figure 2. The ATR-dependent replication stress response 


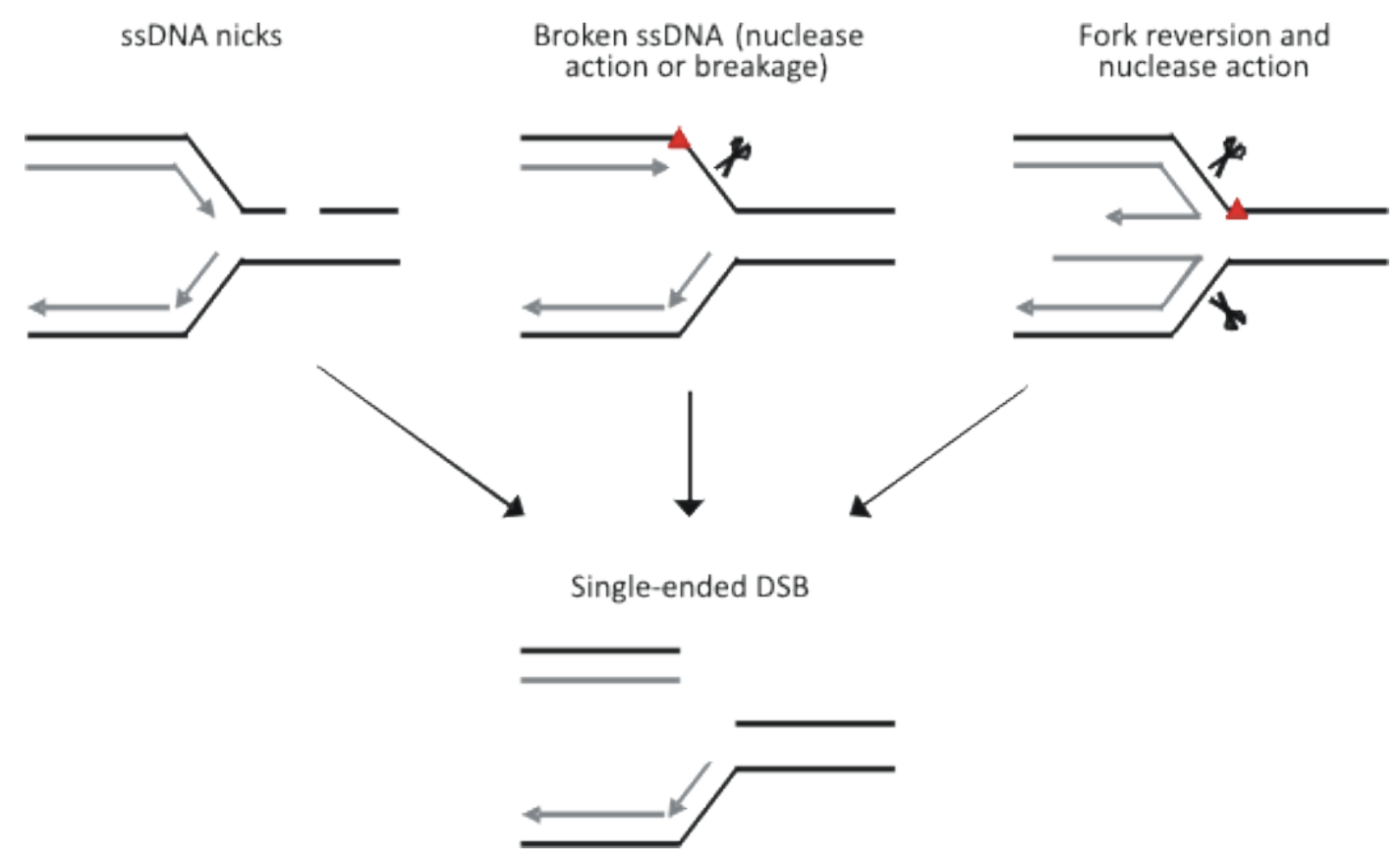

Figure 3. Formation of replication-dependent DNA double strand breaks 
A Single-ended DSB at collapsed fork

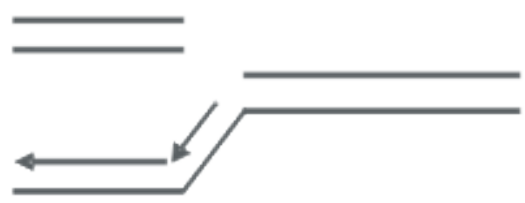

B 5 ' end resection

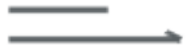

C 3 ' end invasion

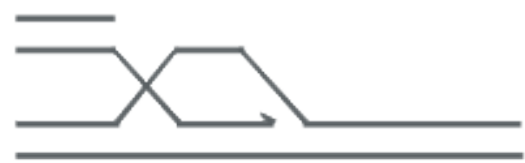

D Replication fork formation

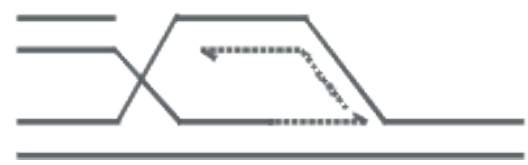

E Separation

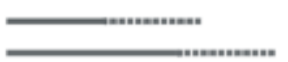

F Reinvasion

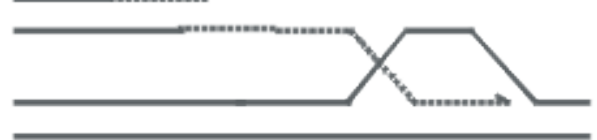

$\mathrm{G}$ Processive replication fork formation

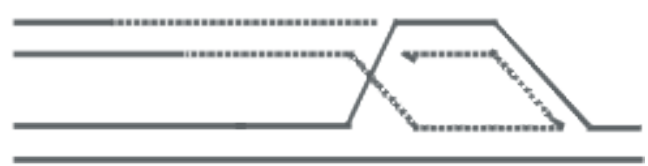

H Resolution

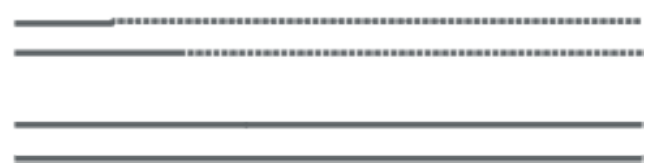

Figure 4. Repair of a collapsed fork by break induced replication 